\title{
COVID-19 vaccine acceptance and its associated factors in Ethiopia: A systematic review and meta-analysis
}

\author{
Birye Dessalegn Mekonnen ${ }^{a, *}$, Banchigizie Adane Mengistu ${ }^{a}$

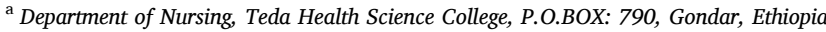

\section{A R T I C L E I N F O}

\section{Keywords:}

Acceptance

COVID-19

Risk factors

Vaccine

Ethiopia

\begin{abstract}
A B S T R A C T
Background: COVID-19 vaccination is considered as an effective intervention for controlling the burden of the pandemic. However, vaccine hesitation is increasing and hindering efforts targeting to reduce the burden of the COVID-19 disease. Hence, determining COVID-19 vaccine acceptance and identifying determinants that would hinder people to vaccinate against COVID-19 is crucial to effectively improve COVID-19 vaccine uptake. In Ethiopia, the pooled proportion of COVID-19 vaccine acceptance and its determinants is not well known. Thus, the aim of this study is to estimate the pooled proportion of COVID-19 vaccine acceptance and its determinants in Ethiopia.

Methods: A systematic search of articles was conducted from PubMed, Scopus, Web of Science, MEDLINE, CINAHL, Science Direct and Cochrane Library. Data were extracted using a data extraction tool which was adapted from the Joanna Briggs Institute. The quality of each included primary studies was evaluated using the Newcastle-Ottawa scale tool. Data analysis was performed using STATA 14. Heterogeneity in studies was assessed using Cochrane $\mathrm{Q}$ and $\mathrm{I}^{2}$ test. Publication bias was assessed using visual inspection of funnel plots and Egger's test. A random effects model was applied to determine the pooled estimates if heterogeneity was exhibited; otherwise, a fixed-effects model was used.

Results: A total of 14 studies involving 6373 participants were included for the final analysis. The pooled proportion of COVID-19 vaccine acceptance in Ethiopia was 56.02\% (95\% CI: 47.84, 64.20). The likelihood of COVID-19 vaccine acceptance was higher among participants who had history of chronic disease (AOR $=1.33$, $95 \%$ CI: $1.09,2.97$ ), good knowledge (AOR $=2.13,95 \%$ CI: $1.59,4.97$ ), positive attitude (AOR $=2.23$, 95\% CI: $1.21,4.66)$, good COVID-19 preventive practice (AOR $=1.97,95 \%$ CI: $1.82,2.12$ ), and high perceived seriousness of COVID-19 (AOR $=3.21,95 \%$ CI: 2.32, 5.98).

Conclusion: More than half participants were willing to accept COVID-19 vaccine. Thus, awareness creation battles about the efficacy and safety of the COVID-19 vaccine should be provided to the community. Besides, policy-makers, health planners and other stakeholders should encourage COVID-19 vaccine uptake behaviors by providing trusted information.

Systematic review and meta-analysis registration: PROSPERO CRD42021264708.
\end{abstract}

\section{Background}

The World Health Organization (WHO) began a global campaign of prevention, early diagnosis, and medical treatment of the coronavirus disease 2019 (COVID-19) following the outbreak that was declared as a pandemic in early 2020. ${ }^{1}$ Subsequently, multiple COVID-19 vaccines were developed and tested across diverse populations in different clinical trials. ${ }^{2,3}$
Vaccination is considered as effective intervention for controlling pandemics and most preventable infectious diseases. ${ }^{4}$ The vaccination utilization level must be high in order to be successful. ${ }^{5}$ Additionally, distribution and equitable access of safe and effective vaccine strongly desires methods to improve vaccine acceptance and sufficient health system capacity.

In recent times, several literatures have reported the effectiveness and safety of COVID-19 vaccines. ${ }^{2,6,7}$ The efficacy of the mRNA-1273

\footnotetext{
Abbreviations: AOR, Adjusted odd ratio; CI, Confidence intervals; COVID-19, Coronavirus disease 2019; PRISMA, Preferred Reporting Items for Systematic review and Meta-analysis; SMP, self-medication practice; WHO, World Health Organization.

* Corresponding author

E-mail addresses: birye22@gmail.com (B.D. Mekonnen), banchiu4@gmail.com (B.A. Mengistu).
} 
vaccine was reported to be $94.1 \%,{ }^{8}$ the BNT162b2 mRNA vaccine has been documented to be $95 \%,{ }^{9}$ that of the ChAdOx $1 \mathrm{nCoV}-19$ vaccine has been reported to be $70.4 \%,{ }^{10}$ and the Gam-COVID-Vac has been documented to be $91.6 \% .^{11}$

Public perceptions, misconceptions and rumors on the vaccines may result in vaccine hesitancy. ${ }^{12,13}$ Over again, vaccine hesitancy would result decreasing vaccine coverage, which further could lead to disease outbreaks including COVID-19. ${ }^{14}$ Hence, understanding vaccine acceptance is crucial as high vaccine hesitancy for existing vaccines could lead to relatively low vaccination coverage. ${ }^{15}$

Despite the efforts to control COVID-19 through vaccination, vaccine hesitation is increasing and hindering efforts targeting to reduce the burden of the disease. ${ }^{16}$ Globally, vaccine hesitancy is considered as a major public health issue because of its substantial increase. ${ }^{17}$ Wrong impression due to accelerated development the vaccine, misinformation, and multiple myths would potentially affect the willingness of population to accept COVID-19 vaccine. ${ }^{18,19}$

COVID-19 vaccination acceptance have been investigated and reported in previous studies. ${ }^{20-23}$ A systematic review and meta-analysis has been reported that the pooled proportion of willingness to COVID-19 vaccination among the general population was $81.65 \% .{ }^{20}$ Another systematic review and meta-analysis conducted has revealed that the pooled proportion of COVID-19 vaccination willingness among healthcare workers was $51 \% .{ }^{21}$ However, these studies have not been included findings from Ethiopia.

Similar to all other parts of the world, many African countries have been implemented COVID-19 vaccines trials to contribute to the global search for vaccines against the COVID-19 pandemic. ${ }^{24}$ Africa need about 1.5 billion doses of COVID-19 vaccine to vaccinate $60 \%$ of its population. ${ }^{25}$ Most African countries including Ethiopia need COVID-19 vaccines from different donating countries to achieve the estimated target. $^{26}$

Though Ethiopia is gaining vaccines from different donating countries, the proportion of COVID-19 vaccine acceptance in the general population is not well known. Except for fragmented studies with varying reports, there are no national prevalence studies conducted on COVID-19 vaccine acceptance in Ethiopia. Moreover, investigating determinants that would hinder people to vaccinate against COVID-19 is not well investigated. It is crucial to warrant the population to have access to reliable and sufficient information regarding this vaccine to raise its acceptance rate. ${ }^{2}$ Hence, by determining COVID-19 vaccine acceptance and identifying associated factors, governments policy-makers, and health authorities, and other stakeholders can design specific vaccine campaigns and the development of evidence-based guidelines to effectively improve COVID-19 vaccine uptake. Thus, the aim of this systematic review and meta-analysis is to estimate the pooled proportion of COVID-19 vaccine acceptance and identify factors associated with COVID- 19 vaccine acceptance.

\section{Methods}

The methods adopted for this systematic review and meta-analysis are consistent with the guidelines detailed on the Preferred Reporting Items for Systematic Reviews and Meta-Analysis (PRISMA) checklist. ${ }^{27}$ The systematic review was prospectively registered on International Prospective Register of Systematic Reviews (PROSPERO) with unique of number CRD42021264708.

\section{Eligibility criteria}

The inclusion criteria for this study were the following ${ }^{1}$ : Studies that investigated COVID-19 vaccine acceptance and/or its determinants in Ethiopia, ${ }^{2}$ observational studies which contain relevant outcomes were included, ${ }^{3}$ studies that had been performed on healthcare workers, ${ }^{4}$ studies that had been conducted and reported in English language, and ${ }^{5}$ articles that had a full-text article publicly available were included. The exclusion criteria of the study were the following ${ }^{1}$ : studies that were qualitative studies, reviews, case reports and letters to editors, and ${ }^{3}$ studies did not have full-text available publicly.

\section{Information sources and search strategy}

A comprehensive search and article retrieval strategy were performed to find potentially relevant articles in the following databases: PubMed, Scopus, Web of Science, MEDLINE, CINAHL, Science Direct and Cochrane Library. In addition, the reference lists of all articles that were considered and searched. Google Scholar, input of content experts and Institutional Digital Library were also searched for gray literature and unpublished papers. The full electronic search strategy was searched using the following search terms: 'COVID-19', 'SARS-CoV-2', 'Coronavirus', 'vaccine', 'vaccination', 'immunization', 'acceptance', 'willingness', 'intention', 'accept', 'factors', 'determinates', 'reasons', 'predictors' and 'Ethiopia'. A combination of appropriate Boolean operators (AND, OR), truncation, and the MeSH terms were used. The searching of articles was conducted from 20th of August to September 10th, 2021.

\section{Study selection}

EndNote X7 (Thomson Reuters, New York, USA) software was used to manage identified and retrieved studies. After removing the duplicated articles from EndNote Library, the titles and abstracts of the remaining articles were assessed independently by two reviewers (BDM and BAM). The full texts of articles were reviewed to confirm eligibility criteria match. Disagreements between the two reviewers were resolved by discussion. The PRISMA flow diagram was used to summarize the study selection processes.

\section{Data extraction and main data items}

All required data from included articles were extracted using a standardized, pre-piloted data extraction format. Two reviewers (BDM and BAM) independently extracted the data using the Joanna Briggs Institute (JBI) data extraction form. ${ }^{28}$ Disagreement during data extraction was resolved by discussion and consensus. Relevant information was collected for each study, including: the first authors' name, region, study year, publication year, study design, study setting, participants, sample size, data collection methods, sampling method, response rate, outcome measures (COVID-19 vaccine acceptance), determinants of vaccine acceptance.

\section{Quality assessment}

The methodologic quality and risk of bias of each studies were assessed using the Newcastle-Ottawa scale (NOS) tool. Two authors (BDM and BAM independently evaluated the risk of bias and any disparity was resolved through discussion and reviewing the articles together. The quality assessment tool was adapted from a nonrandomized study which developed for the quality assessments of metaanalytic results. ${ }^{29}$ The quality appraisal tool has three main themes with a maximum of 10 stars: The first them of the tool focuses on selection (representativeness of the sample, sample size, response rate, sampling technique, ascertainment of the exposure of COVID-19 vaccine) with a maximum of 4 stars; the second them of the tool focuses on comparability (in the context of participant distribution and analyses) with a maximum of 2 stars; and the last them of the tool concerned with outcome (assessment of the outcome; and statistical tests assessment) with a maximum of 3 stars.

\section{Measurement of outcomes}

COVID-19 vaccine acceptance was the main outcomes of this study, 


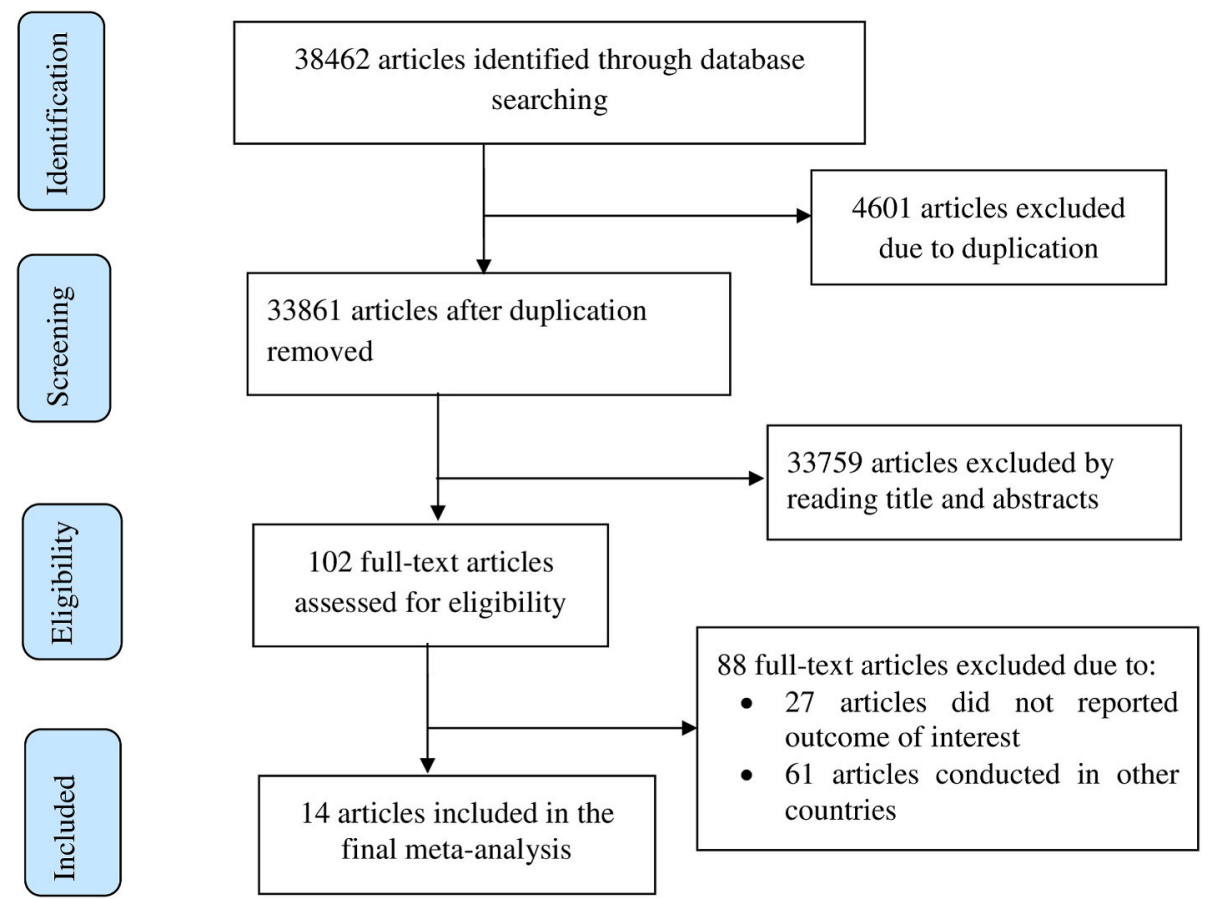

Fig. 1. Flow chart of study selection for systematic review and meta-analysis of COVID-19 vaccine acceptance in Ethiopia, 2021.

which is defined as the willingness to take the COVID-19 vaccine. In the primary studies, participants were asked their willingness to COVID-19 vaccination. Accordingly, participants who respond "yes" were considered as having the willingness to accept the COVID-19 vaccine, whereas participants who respond "No" were considered as having no willingness to accept the COVID-19 vaccine. In this study, identify factors associated with COVID-19 vaccine acceptance was the second outcome of interest, which were measured in the form of the odds ratio (OR). The odds ratio for each identified factor was calculated based on the binary outcome data reported by each original study.

\section{Data processing and analysis}

The individual primary studies were described succinctly using a summary table. Findings were presented using forest plot graphical representation with $95 \%$ confidence interval (CI). We used STATA version 14 statistical software to conduct this meta-analysis. A randomeffects model was used to pool the estimate of COVID-19 vaccine

Table 1

Characteristics of studies included in the systematic review and meta-analysis of COVID-19 vaccine acceptance in Ethiopia, 2021.

\begin{tabular}{|c|c|c|c|c|c|c|c|c|c|c|}
\hline Author & Year & Region & $\begin{array}{l}\text { Study } \\
\text { design }\end{array}$ & Study area & Study population & $\begin{array}{l}\text { Data collection } \\
\text { method }\end{array}$ & $\begin{array}{l}\text { Sample } \\
\text { size }\end{array}$ & Participants & $\begin{array}{l}\text { Vaccine } \\
\text { acceptance (\%) }\end{array}$ & $\begin{array}{l}\text { Quality of } \\
\text { studies }\end{array}$ \\
\hline Nebyu D et al. ${ }^{43}$ & 2021 & $\begin{array}{l}\text { Addis } \\
\text { Ababa }\end{array}$ & $\begin{array}{l}\text { Cross } \\
\text { sectional }\end{array}$ & $\begin{array}{l}\text { Akaki } \\
\text { kality }\end{array}$ & Adult Population & $\begin{array}{l}\text { Face to face } \\
\text { interview }\end{array}$ & 422 & 409 & 80.9 & High \\
\hline Berihun et al. ${ }^{35}$ & 2021 & Amhara & $\begin{array}{l}\text { Cross } \\
\text { sectional }\end{array}$ & Dessie & $\begin{array}{l}\text { Patients with } \\
\text { chronic diseases }\end{array}$ & $\begin{array}{l}\text { Self- } \\
\text { administered }\end{array}$ & 422 & 416 & 59.4 & High \\
\hline $\begin{array}{l}\text { Mose A and } \\
\text { Yeshaneh } \mathrm{A}^{33}\end{array}$ & 2021 & SNNPR & $\begin{array}{l}\text { Cross } \\
\text { sectional }\end{array}$ & $\begin{array}{l}\text { Gurage } \\
\text { zone }\end{array}$ & Pregnant women & $\begin{array}{l}\text { Face to face } \\
\text { interview }\end{array}$ & 396 & 396 & 70.7 & Medium \\
\hline Abebe et al. ${ }^{30}$ & 2021 & SNNPR & $\begin{array}{l}\text { Cross } \\
\text { sectional }\end{array}$ & $\begin{array}{l}\text { Gurage } \\
\text { zone }\end{array}$ & Adult Population & $\begin{array}{l}\text { Self- } \\
\text { administered }\end{array}$ & 501 & 492 & 62.6 & High \\
\hline $\begin{array}{l}\text { Molalegn } \\
\text { Mesele }^{31}\end{array}$ & 2021 & SNNPR & $\begin{array}{l}\text { Cross } \\
\text { sectional }\end{array}$ & Sodo town & Adult Population & $\begin{array}{l}\text { Self- } \\
\text { administered }\end{array}$ & 424 & 415 & 45.5 & High \\
\hline Belsti et al. ${ }^{40}$ & 2021 & Ethiopia & $\begin{array}{l}\text { Cross } \\
\text { sectional }\end{array}$ & Ethiopia & Adult Population & Online survey & 1184 & 1184 & 42.2 & High \\
\hline $\begin{array}{l}\text { Alle YF and } \\
\text { Oumer }^{36}\end{array}$ & 2021 & Amhara & $\begin{array}{l}\text { Cross } \\
\text { sectional }\end{array}$ & Debre tabor & $\begin{array}{l}\text { Healthcare } \\
\text { workers }\end{array}$ & $\begin{array}{l}\text { Self- } \\
\text { administered }\end{array}$ & 327 & 319 & 42.3 & Medium \\
\hline Handebo et al. ${ }^{39}$ & 2021 & Amhara & $\begin{array}{l}\text { Cross } \\
\text { sectional }\end{array}$ & Gondar & School teachers & $\begin{array}{l}\text { Self- } \\
\text { administered }\end{array}$ & 323 & 301 & 54.8 & Medium \\
\hline $\begin{array}{l}\text { Zewude B, } \\
\quad \text { Belachew A }\end{array}$ & 2021 & Ethiopia & $\begin{array}{l}\text { Cross } \\
\text { sectional }\end{array}$ & Ethiopia & $\begin{array}{l}\text { Healthcare } \\
\text { workers }\end{array}$ & $\begin{array}{l}\text { Self- } \\
\text { administered }\end{array}$ & 384 & 232 & 63.4 & Medium \\
\hline $\begin{array}{l}\text { Guangul BA } \\
\text { et al. }{ }^{42}\end{array}$ & 2021 & Ethiopia & $\begin{array}{l}\text { Cross } \\
\text { sectional }\end{array}$ & Ethiopia & $\begin{array}{l}\text { Healthcare } \\
\text { workers }\end{array}$ & Online survey & 1110 & 668 & 72.2 & Medium \\
\hline Angelo et al. ${ }^{32}$ & 2021 & SNNPR & $\begin{array}{l}\text { Cross } \\
\text { sectional }\end{array}$ & Mizan tepi & $\begin{array}{l}\text { Healthcare } \\
\text { workers }\end{array}$ & $\begin{array}{l}\text { Self- } \\
\text { administered }\end{array}$ & 423 & 405 & 48.4 & High \\
\hline Taye BT et al. ${ }^{37}$ & 2021 & Amhara & $\begin{array}{l}\text { Cross } \\
\text { sectional }\end{array}$ & $\begin{array}{l}\text { Debre } \\
\text { Berhan }\end{array}$ & Students & $\begin{array}{l}\text { Self- } \\
\text { administered }\end{array}$ & 423 & 423 & 69.3 & High \\
\hline $\begin{array}{l}\text { Hailemariam } \\
\text { et al. }\end{array}$ & 2021 & SNNPR & $\begin{array}{l}\text { Cross } \\
\text { sectional }\end{array}$ & $\begin{array}{l}\text { Bench- } \\
\text { sheko zone }\end{array}$ & Pregnant women & $\begin{array}{l}\text { Self- } \\
\text { administered }\end{array}$ & 423 & 412 & 31.3 & High \\
\hline Shitu et al. ${ }^{38}$ & 2021 & Amhara & $\begin{array}{l}\text { Cross } \\
\text { sectional }\end{array}$ & Gondar & School teachers & $\begin{array}{l}\text { Self- } \\
\text { administered }\end{array}$ & 302 & 301 & 40.9 & Medium \\
\hline
\end{tabular}




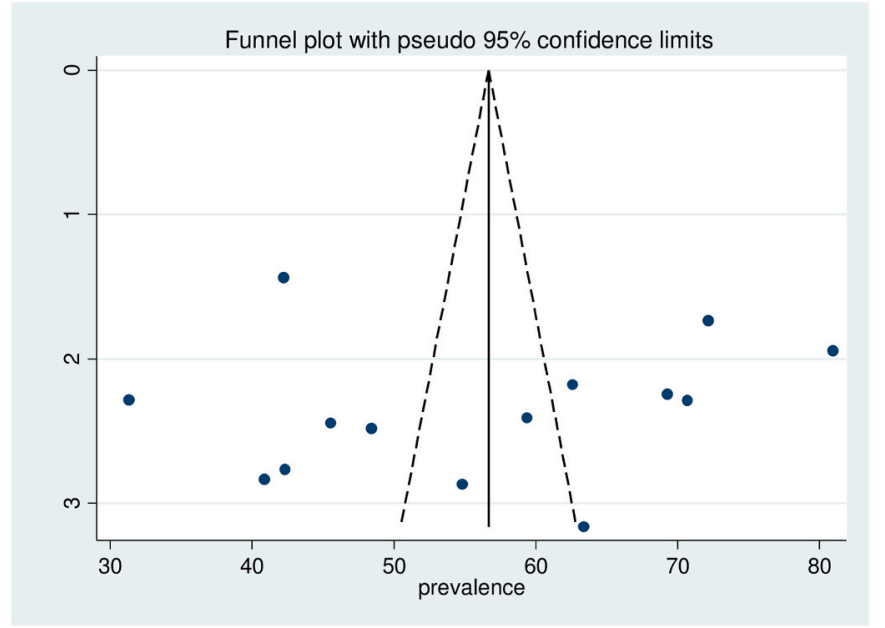

Fig. 2. Funnel plot assessed for publication bias in the studies conducted on of COVID-19 vaccine acceptance in Ethiopia, 2021.

acceptance if substantial heterogeneity was exhibited between studies; otherwise, a fixed-effects model was used. The Cochran's Q test and $\mathrm{I}^{2}$ were used to detect heterogeneity between the studies. The variation in the pooled estimates of the proportion of COVID-19 vaccine acceptance was adjusted through subgroup analysis. As a result, subgroup analysis was done based on study region, study population, and data collection methods to reduce the random variations among the point estimates of the primary study. In addition, evidence of publication bias was checked using visual inspection of funnel plots asymmetry, and weighted Egger's regression test with $\mathrm{p}$ - value of less than 0.05 as a cutoff point to declare the presence of publication bias. The results indicated that evidence of publication bias was not observed. Furthermore, a sensitivity analysis was conducted to check the stability of the summary estimate.

\section{Results}

\subsection{Study selection}

Overall, 38462 potentially relevant articles were retrieved from which 33861 unique studies. Two reviewers (BDM and BAM) independently assessed articles based on their titles and abstracts which result in the exclusion of 33759 articles. One hundred two full-text articles were assessed for eligibility based on the inclusion and exclusion criteria, which result further exclusion of 88 articles. Finally, 14 articles were included in the final analysis (Fig. 1).

\subsection{Study characteristics}

All of the articles included in this meta-analysis were cross-sectional designs. Of fourteen studies included, 5 were from SNNPR region, ${ }^{30-34} 5$ were from Amhara region, ${ }^{35-39} 3$ were nationwide studies ${ }^{40-42}$ and 1 was from Addis Ababa city administration. ${ }^{43}$ All articles were published in 2021. In this study, a total of 6373 participants were included from an estimated 7064 sample size, yielding $90.2 \%$ response rate. The proportion of COVID-19 vaccine acceptance reported in the selected studies varied from $31.3 \%$ to $80.9 \%$. As for the evaluation of COVID-19 vaccine acceptance, ten of the included studies utilized self-designed questionnaires, two studies used face to face interview, and the other two used online survey. More than half ${ }^{8}$ of studies had high quality, and the remaining 6 studies had medium quality (Table 1).

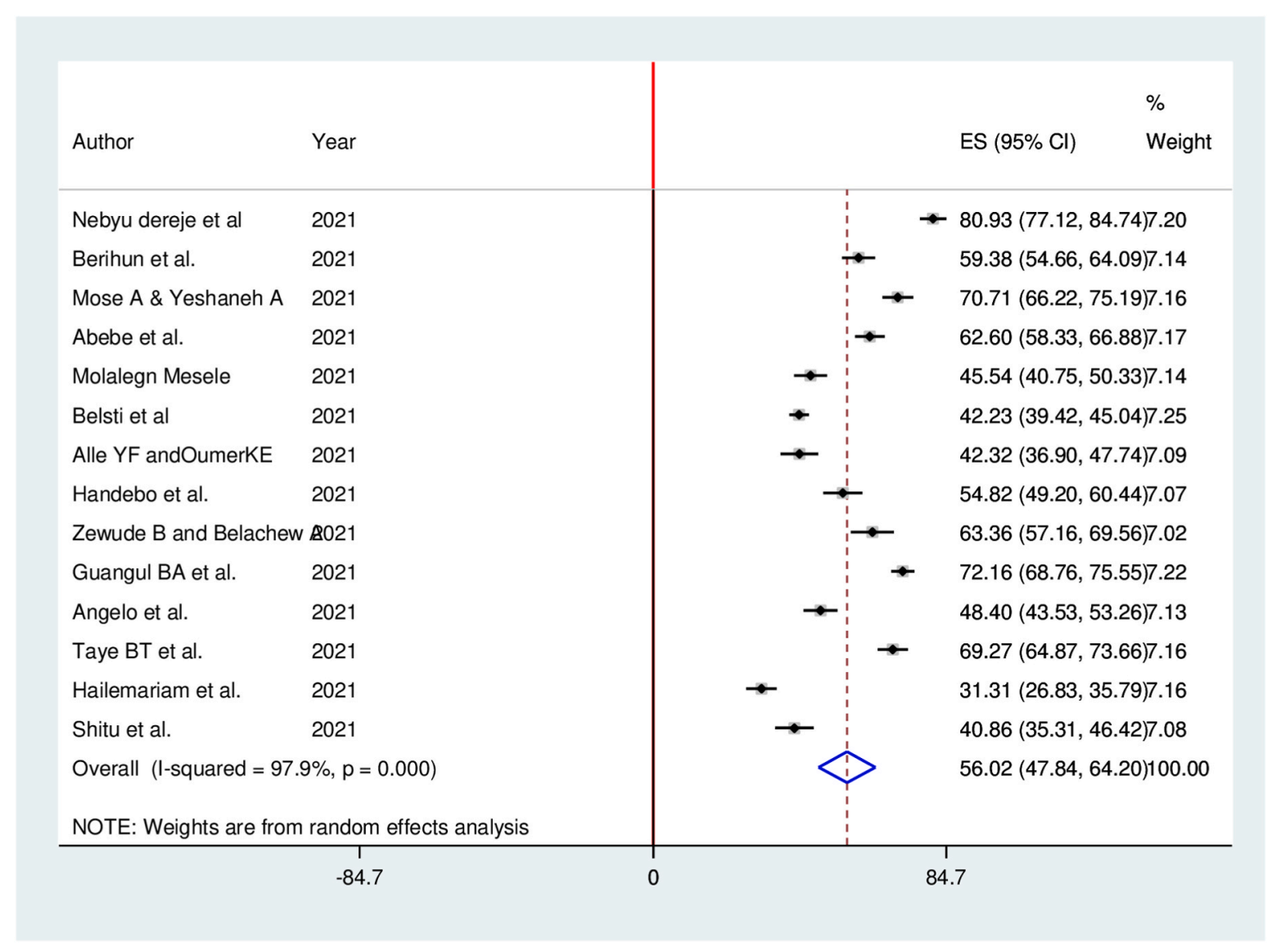

Fig. 3. Forest plot of the pooled proportion of COVID-19 vaccine acceptance in Ethiopia, 2021. 


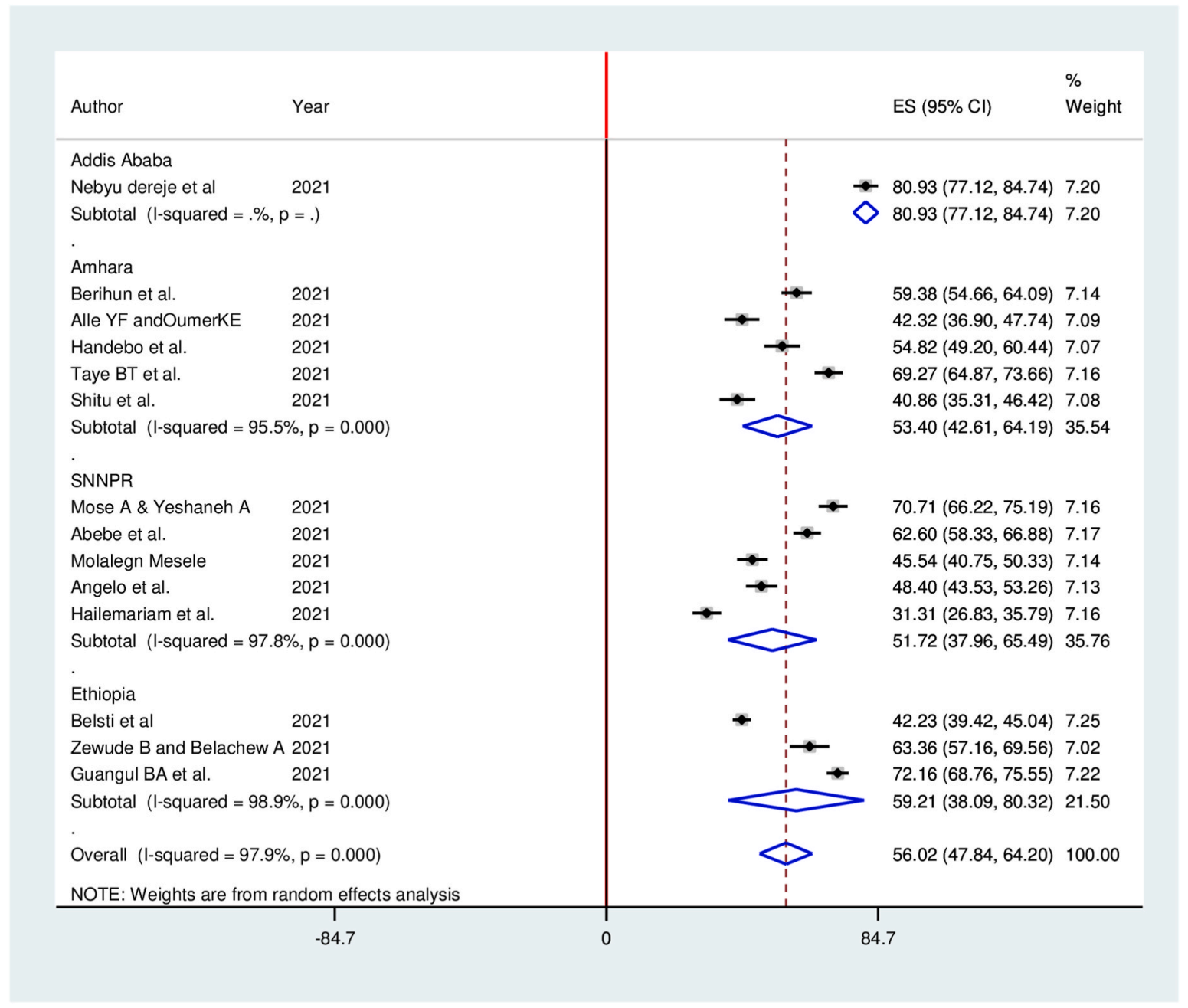

Fig. 4. Sub-group analysis (by region) of the pooled proportion of COVID-19 vaccine acceptance in Ethiopia, 2021.

\subsection{Publication bias and sensitivity analysis}

In this systematic review and meta-analysis, sensitivity analysis was conducted using the random-effects model for the estimates of COVID19 vaccine acceptance. The results of the sensitivity analysis suggested that there is no influential study as none of the points estimate outside of the overall $95 \%$ confidence interval. Visual inspection of the funnel plot indicated that there is symmetrical distribution of studies included in the review, and Egger's test was not statistically significant $(P=0.821)$ suggesting the absence of publication bias for COVID-19 vaccine acceptance (Fig. 2).

\subsection{Meta-analysis of COVID-19 vaccine acceptance}

Fourteen studies reported the acceptance of COVID-19 vaccine in a total of 6373 study participants. The pooled proportion of COVID-19 vaccine acceptance in Ethiopia was found to be $56.02 \%$ (95\% CI: 47.84, 64.20). In this meta-analysis, a random effects model was executed as high heterogeneity $\left(\mathrm{I}^{2}=97.9 \%, \mathrm{P} \leq 0.001\right)$ was detected within the included studies (Fig. 3).

\subsection{Subgroup analysis of COVID-19 vaccination acceptance}

Subgroup analyses for the meta-analysis was implemented to clarify the source of heterogeneity Because of severe heterogeneity observed among selected studies. The subgroup analysis was implemented based on study region, study population, and data collection methods.
However, no considerable difference between subgroup heterogeneity and overall heterogeneity exhibited in subgroup analysis, indicating that the heterogeneity was not associated with study region, study population, and data collection methods (Fig. 4, Fig. 5, Fig. 6).

\subsection{Meta-analysis of factors associated with COVID-19 vaccine acceptance}

In this meta-analysis, variables common to all participants were pooled quantitatively to examine if they are significantly associated with COVID-19 vaccine acceptance. Nevertheless, some factors were not pooled because of inconsistent categorization in the primary studies. Those determinants reported in more than one original studies were included in this meta-analysis. Accordingly, having good knowledge of the COVID-19 vaccine, having a positive attitude towards COVID-19 vaccine, good preventive practices, history of chronic illness, and having high perceived seriousness of COVID-19 were significant factors associated with COVID-19 vaccine acceptance.

Study participants with a history of chronic disease were 1.33 times (AOR $=1.33,95 \%$ CI: $1.09,2.97$ ) more likely to accept the COVID-19 vaccine than study participants without a history of chronic disease. Study participants who had good knowledge about the COVID-19 vaccine were 2.13 times (AOR $=2.13,95 \%$ CI: $1.59,4.97$ ) more likely to accept the COVID- 19 vaccine as compared with study participants with poor knowledge. Study participants who had positive attitude towards the COVID-19 vaccine were 2.23 times (AOR $=2.23$, 95\% CI: $1.21,4.66$ ) more likely to accept the COVID- 19 vaccine than those study 


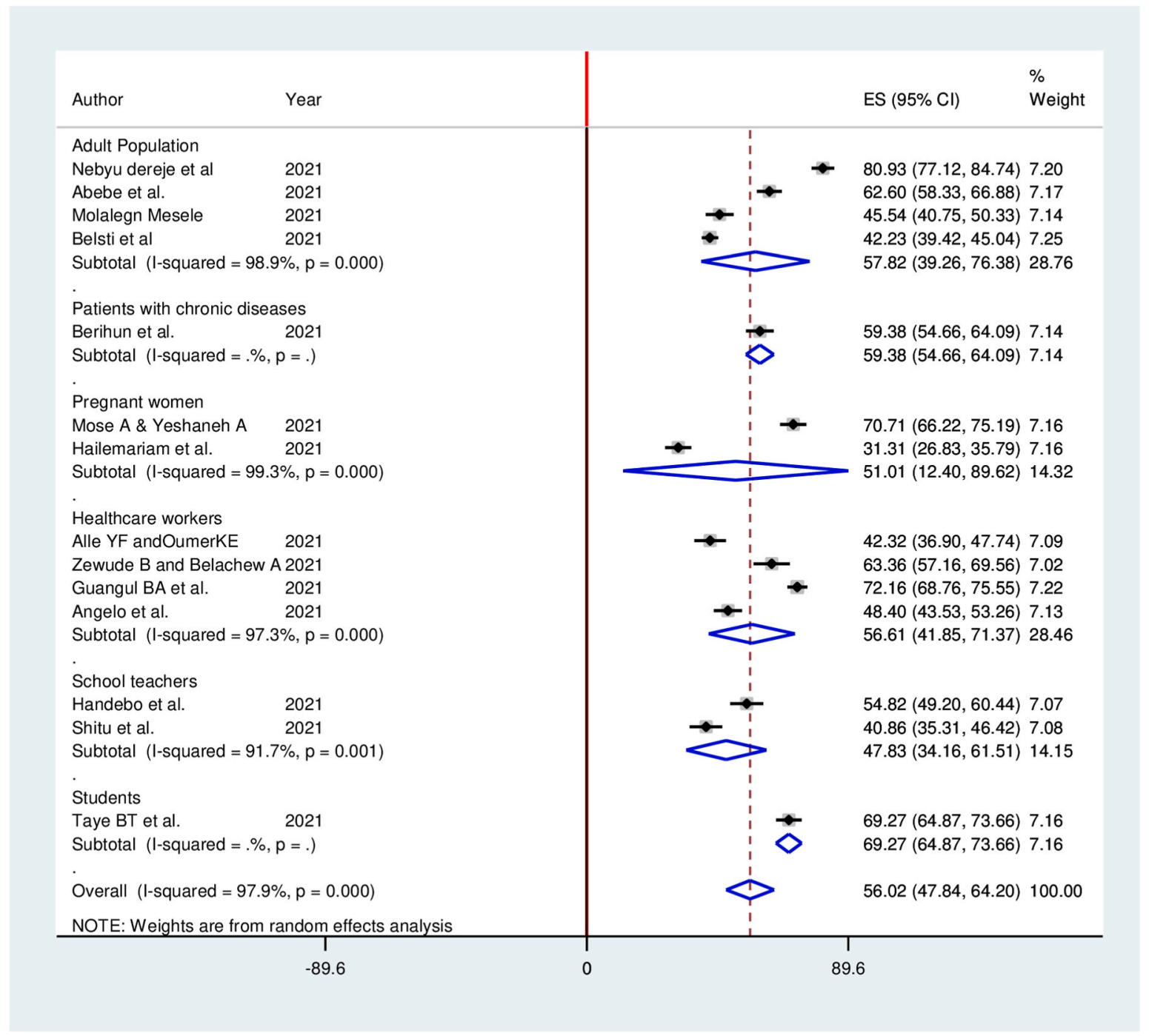

Fig. 5. Sub-group analysis (by study population) of the pooled proportion of COVID-19 vaccine acceptance in Ethiopia, 2021.

participants with negative attitude. The odds of COVID- 19 vaccine acceptance was 3.21 times (AOR $=3.21,95 \%$ CI: 2.32 , 5.98) among study participants who had high perceived seriousness of COVID-19 than those study participants who had low perceived seriousness of COVID-19. The likelihood of COVID- 19 vaccine acceptance was 1.97 times (AOR $=1.97,95 \%$ CI: 1.82, 2.12) among study participants who had good preventive practice of COVID-19 than those study participants who had poor preventive practice of COVID-19 (Table 2).

\section{Discussion}

The findings of this study indicated that more than half of the participants were willing to accept COVID-19 vaccine. This observed low COVID-19 vaccine acceptance could attribute to public exposure to misconception and concerns over the safety of the COVID-19 vaccine. Evidence suggests that public exposure to misinformation and concerns over the safety of COVID-19 vaccines could be contributing to low intentions to be vaccinated. ${ }^{44-46}$ It is believed that the wide uptake of COVID-19 vaccine could contribute to the development of herd immunity and guard the public against COVID-19. ${ }^{47}$ Hence, this finding implies the need for better enactment to address public trust, acceptability, benefit and concern over the safety of the approved COVID-19 vaccine.

Results of this systematic review and meta-analysis indicated that the pooled proportion of COVID-19 vaccine acceptance in Ethiopia was found to be $56.02 \%$. The result of this study was in line with different systematic review and meta-analysis which reported pooled proportion of COVID-19 vaccine acceptance as $60.1 \%{ }^{48}$ and $60 \% .{ }^{23}$ However, the finding was lower than a systematic review and meta-analysis that reported the pooled proportion of willingness to COVID-19 vaccination among the general population to be $81.65 \% .{ }^{20}$ This could attribute to variations in the spread and burden of the COVID-19 pandemic across the countries. The discrepancy could be also due differences in the respondents' local norms and cultures, and exposure to credible social media disseminating factual information regarding COVID-19 vaccine. Moreover, the variation could be explained by differences in awareness on the severity of COVID-19, access to health care service.

Results of the subgroup analysis indicated that the pooled proportion of COVID-19 vaccine acceptance among healthcare workers in Ethiopia was $56.61 \%$. The result of this study was in line with a systematic review and meta-analysis which reported pooled proportion of COVID-19 vaccine acceptance as $51 \%{ }^{21}$ This implies that a considerable proportion of healthcare workers were hesitant towards COVID-19 vaccine, which hinder their recommendation of vaccination to their patients. Evidence indicates that the attitude of the healthcare workers toward COVID-19 vaccine were found to influence their intention to suggest the vaccine to their patients and general population. ${ }^{49}$ Hence, future prioritized education needs to involve healthcare workers to influence their own use of the vaccine and to be accepted by the population. 


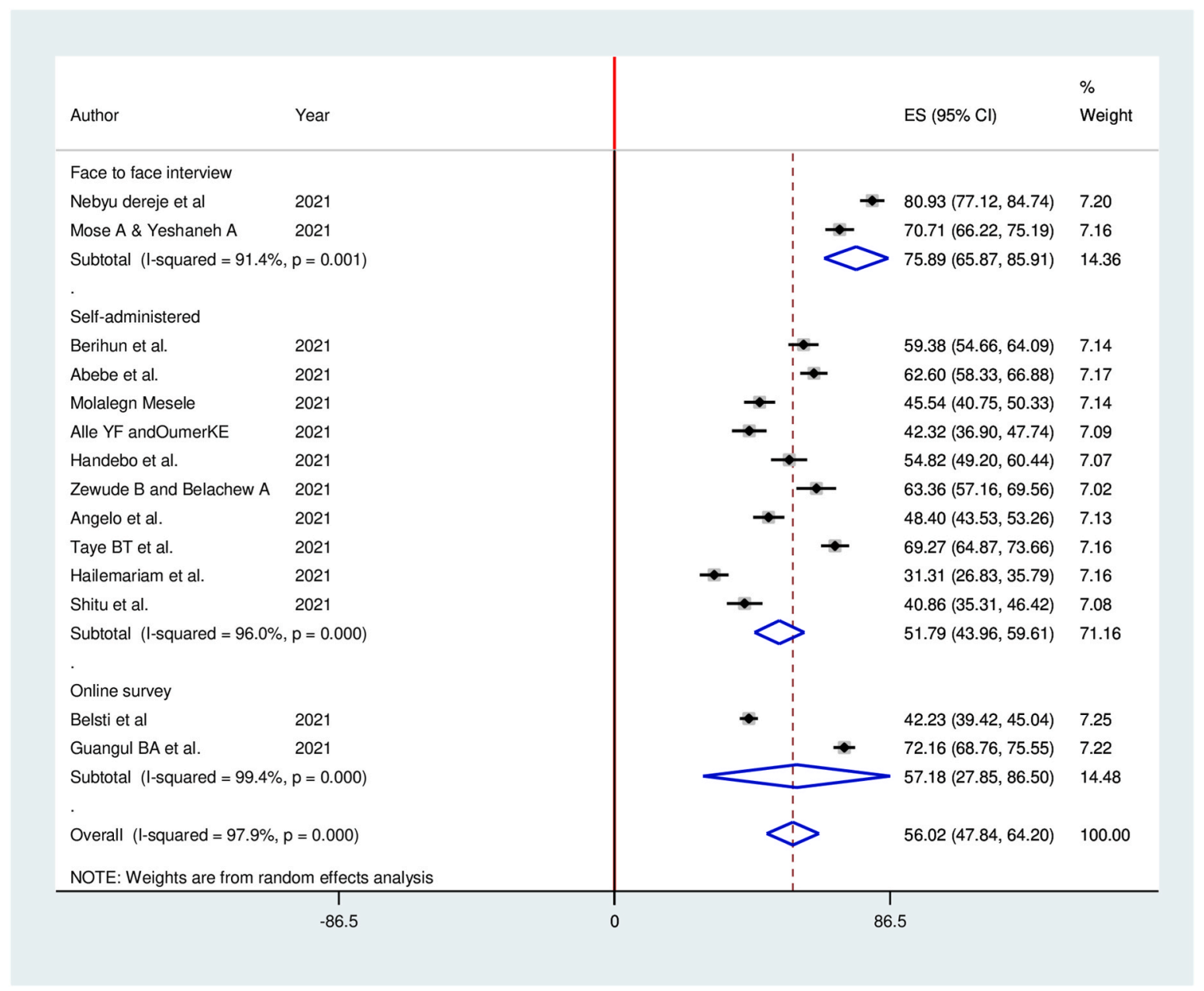

Fig. 6. Sub-group analysis (by data collection method) of the pooled proportion of COVID-19 vaccine acceptance in Ethiopia, 2021.

This study identified that having history of chronic disease had significantly associated with COVID vaccine acceptance. Participants with a history of chronic disease were more likely to accept the COVID19 vaccine than study participants without a history of chronic disease. This result is supported by a report from $\mathrm{WHO},{ }^{50}$ and a study conducted in Australia. ${ }^{51}$ This finding highlights the need to create platform that could enable individuals with history of chronic disease to be vaccinated against COVID-19 vaccine.

Having good knowledge about the COVID-19 vaccine had significantly associated with willingness to accept the COVID vaccine. Participants who had good knowledge about the COVID-19 vaccine were more likely to accept the COVID- 19 vaccine as compared with study participants with poor knowledge. This finding implies that improving knowledge regarding the benefit, effectiveness and safety of the COVID19 vaccine could be one of the strategies for achieving targeted vaccination coverage in the general population. This finding is also explained by having good knowledge considered as an engine to take actions regarding a certain behaviour, as it helps individuals to understand the seriousness of the disease, and to know the benefit of the vaccination program. This result is supported by survey carried out in England ${ }^{52}$ and Southeast Asia. ${ }^{53}$

Positive attitude towards the COVID-19 vaccine was another significant factor associated with COVID-19 vaccine acceptance. Study participants who had positive attitude towards the COVID-19 vaccine were more likely to accept the COVID- 19 vaccine than those study participants with negative attitude. This implies that the role of positive attitude towards COVID- 19 vaccination is crucial. This study also identified that participants with high perceived seriousness of COVID-19 infection were more likely to accept the COVID- 19 vaccination than those with low perceived seriousness of COVID-19 infection. This finding is in line with studies reported from Indonesia ${ }^{54}$ China. ${ }^{55}$ This could be due to the fact that people would take measures to avoid any risk if they think they are vulnerable to it. Evidence indicated that individuals' readiness of taking the recommended action would be influence by their level of perception to the positive consequences that are caused by taking an action. ${ }^{56}$

Furthermore, having good preventive practice towards COVID-19 disease was significantly associated with COVID-19 vaccine acceptance. The likelihood of COVID- 19 vaccine acceptance was higher among study participants who had good preventive practice of COVID19 than those study participants who had poor preventive practice of COVID-19. This finding is in line with studies reported from the Democratic Republic of the Congo ${ }^{57}$ and Middle Eastern Population. ${ }^{58}$ This could be due to individuals who had good practice knowing the burden of COVID-19 infection on the health of the general population.

Lastly, the study has the following limitations. First, generalizability of the finding may not be established as the representability of the sample size was uncertain in most studies, and uncertainty of Internet access to complete an online survey. Hence, subgroup analysis was performed according to the sampling method to have acceptable validity. Second, some determinants were not examined due to inconsistent categorization, and limitations of the data in the primary studies. Besides, temporal relationships between outcome variable and predictors couldn't be established as all included studies were cross sectional. Finally, the study may not be representative of the national reaction to the COVID-19 vaccine as it didn't include studies from all regions of the 
Table 2

Factors associated with COVID-19 vaccine acceptance in Ethiopia: a systematic review and meta-analysis, 2021.

\begin{tabular}{|c|c|c|c|c|}
\hline Variables & $\begin{array}{l}\text { Included } \\
\text { studies }\end{array}$ & $\begin{array}{l}\text { OR }(95 \% \\
\text { CI) }\end{array}$ & $\begin{array}{l}\text { Pooled OR } \\
(95 \% \mathrm{CI})\end{array}$ & $\begin{array}{l}\text { Heterogeneity }\left(\mathrm{I}^{2},\right. \\
\text { p-value) }\end{array}$ \\
\hline $\begin{array}{l}\text { History } \\
\text { Chronic } \\
\text { disease }\end{array}$ & $\begin{array}{l}\text { Abebe et al. } \\
\text { Angelo et al. }\end{array}$ & $\begin{array}{l}1.40 \\
(.07 \\
2.11) \\
1.15 \\
(1.06, \\
2.10)\end{array}$ & $\begin{array}{l}1.33 \\
(1.09 \\
2.97)\end{array}$ & $0.0 \%, 0.667$ \\
\hline $\begin{array}{l}\text { Good } \\
\text { knowledge }\end{array}$ & $\begin{array}{l}\text { Berihun et al. } \\
\text { Mose A \& } \\
\text { Yeshaneh A } \\
\text { Abebe et al. } \\
\text { Taye BT et al. } \\
\text { Hailemariam } \\
\text { et al. }\end{array}$ & $\begin{array}{l}1.93 \\
(1.36, \\
2.45) \\
1.78 \\
(1.38, \\
2.19) \\
2.41 \\
(1.47, \\
3.87) \\
2.15 \\
(1.32, \\
3.14) \\
1.52 \\
(1.12, \\
3.14)\end{array}$ & $\begin{array}{l}2.13 \\
(1.59 \\
4.97)\end{array}$ & $75.6 \%, 0.003$ \\
\hline $\begin{array}{l}\text { Positive } \\
\text { attitude }\end{array}$ & $\begin{array}{l}\text { Berihun et al. } \\
\text { Angelo et al. }\end{array}$ & $\begin{array}{l}2.06 \\
(1.19 \\
3.83) \\
2.64 \\
(1.77, \\
5.37)\end{array}$ & $\begin{array}{l}2.23 \\
(1.21 \\
4.66)\end{array}$ & $0.0 \%, 0.088$ \\
\hline $\begin{array}{l}\text { High } \\
\text { perceived } \\
\text { severity }\end{array}$ & $\begin{array}{l}\text { Hailemariam } \\
\text { et al. } \\
\text { Shitu et al. }\end{array}$ & $\begin{array}{l}3.52 \\
(2.41 \\
5.78) \\
2.42 \\
(1.96 \\
5.88)\end{array}$ & $\begin{array}{l}3.21 \\
(2.32, \\
5.98)\end{array}$ & $0.0 \%, 0.397$ \\
\hline $\begin{array}{l}\text { Goo } \\
\text { preventive } \\
\text { practice }\end{array}$ & $\begin{array}{l}\text { Mose A \& } \\
\text { Yeshaneh A } \\
\text { Angelo et al. } \\
\text { Taye BT et al. }\end{array}$ & $\begin{array}{l}2.21 \\
(2.05, \\
2.38) \\
1.12 \\
(1.06, \\
2.03) \\
1.12 \\
(1.04, \\
2.86)\end{array}$ & $\begin{array}{l}1.97 \\
(1.82 \\
2.12)\end{array}$ & $96.1 \%, 0.000$ \\
\hline
\end{tabular}

country.

\section{Conclusions}

This study showed that more than half participants were willing to the accept COVID-19 vaccine. However, substantial number of people were not to be vaccinated against COVID-19, which indicated that vaccine acceptability still needs more attention. The likelihood of COVID-19 vaccine acceptance was higher among participants who had history of chronic disease, good knowledge, positive attitude, good COVID-19 preventive practice, and with high perceived seriousness of COVID-19. Thus, awareness creation battles about the efficacy and safety of the COVID- 19 vaccine should be provided to the community with collaboration effort of all COVID- 19 vaccine taskforce established by the Ethiopia's Ministry of Health, regional and zonal health offices, and public health institute. Besides, policy-makers, health planners and other stakeholders should encourage COVID-19 vaccine uptake behaviors by providing trusted information about the COVID-19 vaccine in all regions of Ethiopia. Moreover, better public health messaging and health education targeting increasing knowledge, and changing attitude towards COVID-19 vaccine should be disseminated to the general population.

\section{Funding}

No funding has been received for this systematic review and metaanalysis.

\section{Availability of data and materials}

All relevant data generated and analyzed in the analysis process is included in this article.

\section{Ethics approval and consent to participate}

Not applicable, since this is systematic review and meta-analysis.

\section{Consent for publication}

Not applicable.

\section{Declaration of competing interest}

The authors declare that they have no competing interest.

\section{Acknowledgements}

The authors would like to thank the authors of the included primary studies, which used as source of information to conduct this systematic review and meta-analysis.

\section{References}

1 Sage W. WHO SAGE Values Framework for the Allocation and Prioritization of COVID19 Vaccination. 2020.

2 Dror AA, Eisenbach N, Taiber S, et al. Vaccine hesitancy: the next challenge in the fight against COVID-19. Eur J Epidemiol. 2020;35(8):775-779.

3 Shrotri M, Swinnen T, Kampmann B, Parker EP. An interactive website tracking COVID-19 vaccine development. Lancet Global Health. 2021;9(5):e590-e592.

4 Hajj Hussein I, Chams N, Chams S, et al. Vaccines through centuries: major cornerstones of global health. Front Public Health. 2015;3:269.

5 Betsch C, Böhm R, Korn L, Holtmann C. On the benefits of explaining herd immunity in vaccine advocacy. Nat Hum Behav. 2017;1(3):1-6.

6 Lazarus JV, Ratzan SC, Palayew A, et al. A global survey of potential acceptance of a COVID-19 vaccine. Nat Med. 2021;27(2):225-228.

7 Fisher KA, Bloomstone SJ, Walder J, Crawford S, Fouayzi H, Mazor KM. Attitudes toward a potential SARS-CoV-2 vaccine: a survey of US adults. Ann Intern Med. 2020; 173(12):964-973.

8 Baden LR, El Sahly HM, Essink B, et al. Efficacy and safety of the mRNA-1273 SARSCoV-2 vaccine. N Engl J Med. 2021;384(5):403-416.

9 Polack FP, Thomas SJ, Kitchin N, et al. Safety and efficacy of the BNT162b2 mRNA Covid-19 vaccine. $N$ Engl J Med. 2020.

10 Voysey M, Clemens SAC, Madhi SA, et al. Safety and efficacy of the ChAdOx $1 \mathrm{nCoV}$ 19 vaccine (AZD1222) against SARS-CoV-2: an interim analysis of four randomised controlled trials in Brazil, South Africa, and the UK. Lancet. 2021;397(10269): 99-111.

11 Logunov DY, Dolzhikova IV, Shcheblyakov DV, et al. Safety and efficacy of an rAd26 and rAd5 vector-based heterologous prime-boost COVID-19 vaccine: an interim analysis of a randomised controlled phase 3 trial in Russia. Lancet. 2021;397(10275): 671-681.

12 Goldenberg MJ. Public misunderstanding of science? Reframing the problem of vaccine hesitancy. Perspect Sci. 2016;24(5):552-581.

13 Troiano G, Nardi A. Vaccine Hesitancy in the Era of COVID-19. Public Health; 2021.

14 Dubé E, Gagnon D, Nickels E, Jeram S, Schuster M. Mapping vaccine hesitancy - country-specific characteristics of a global phenomenon. Vaccine. 2014; 32(49):6649-6654.

15 Van Doremalen N, Bushmaker T, Morris DH, et al. Aerosol and surface stability of SARS-CoV-2 as compared with SARS-CoV-1. N Engl J Med. 2020;382(16):1564-1567.

16 Afolabi AA, Ilesanmi OS. Dealing with vaccine hesitancy in Africa: the prospective COVID-19 vaccine context. Pan Afr Med J. 2021;38.

17 Crescitelli MD, Ghirotto L, Sisson H, et al. A meta-synthesis study of the key elements involved in childhood vaccine hesitancy. Publ Health. 2020;180:38-45.

18 Paul E, Steptoe A, Fancourt D. The Lancet Regional Health-Europe Attitudes towards vaccines and intention to vaccinate against COVID-19: Implications for public health communications. Lancet Reg Health Eur. 2021;1.

19 Ullah I, Khan KS, Tahir MJ, Ahmed A, Harapan H. Myths and conspiracy theories on vaccines and COVID-19: potential effect on global vaccine refusals. Vacunas. 2021;22 (2):93-97.

20 Wang Q, Yang L, Jin H, Lin L. Vaccination against COVID-19: a systematic review and meta-analysis of acceptability and its predictors. Prev Med. 2021:106694. 
21 Luo C, Yang Y, Liu Y, et al. Intention to COVID-19 vaccination and associated factors among health care workers: a systematic review and meta-analysis of cross-sectional studies. Am J Infect Control. 2021.

22 Abdulmoneim SA, Aboelsaad IAF, Hafez DMH, et al. Systematic Review and MetaAnalysis on COVID-19 Vaccine Hesitancy. medRxiv; 2021.

23 Robinson E, Jones A, Daly M. International estimates of intended uptake and refusal of COVID-19 vaccines: a rapid systematic review and meta-analysis of large nationally representative samples. medRxiv. 2020.

24 Makoni M. COVID-19 vaccine trials in Africa. Lancet Respir Med. 2020;8(11): e79-e80.

25 Gostin LO, Karim SA, Mason Meier B. Facilitating access to a COVID-19 vaccine through global health law. J Law Med Ethics. 2020;48(3):622-626.

26 Nkengasong JN, Ndembi N, Tshangela A, Raji T. COVID-19 Vaccines: How to Ensure Africa Has Access. Nature Publishing Group; 2020.

27 Moher D, Liberati A, Tetzlaff J, Altman D. The preferred reporting Items for systematic reviews and meta-analyses group.(2009). Preferred reporting items for systematic reviews and meta-analyses: the PRISMA statement. J Clin Epidemiol. 2009; 62:1006-1012.

28 Munn Z, Tufanaru C, Aromataris E. JBI's systematic reviews: data extraction and synthesis. AJN Am J Nurs. 2014;114(7):49-54.

29 Wells G, Shea B, O'Connell D, Peterson J, Welch V. Losos Met Al. The Newcastle-Ottawa Scale (NOS) for Assessing the Quality of Nonrandomised Studies in Meta-Analyses. 2012.

30 Abebe H, Shitu S, Mose A. Understanding of COVID-19 vaccine knowledge, attitude, acceptance, and determinates of COVID-19 vaccine acceptance among adult population in Ethiopia. Infect Drug Resist. 2021;14:2015.

31 Mesele M. COVID-19 vaccination acceptance and its associated factors in Sodo Town, Wolaita Zone, Southern Ethiopia: cross-sectional study. Infect Drug Resist. 2021;14: 2361.

32 Angelo AT, Alemayehu DS, Dachew AM. Health care workers intention to accept COVID-19 vaccine and associated factors in southwestern Ethiopia, 2021. PLoS One. 2021;16(9), e0257109.

33 Mose A, Yeshaneh A. COVID-19 vaccine acceptance and its associated factors among pregnant women attending antenatal care clinic in southwest Ethiopia: Institutionalbased cross-sectional study. Int J Gen Med. 2021;14:2385.

34 Hailemariam S, Mekonnen B, Shifera N, et al. Predictors of pregnant women's intention to vaccinate against coronavirus disease 2019: a facility-based crosssectional study in southwest Ethiopia. SAGE Med. 2021;9, 20503121211038454.

35 Berihun G, Walle Z, Berhanu L, Teshome D. Acceptance of COVID-19 vaccine and determinant factors among patients with chronic disease visiting dessie comprehensive specialized hospital, Northeastern Ethiopia. Patient Prefer Adherence. 2021; 15:1795.

36 Alle YF, Oumer KE. Attitude and associated factors of COVID-19 vaccine acceptance among health professionals in Debre Tabor Comprehensive Specialized Hospital, North Central Ethiopia; 2021: cross-sectional study. Virusdisease. 2021;32(2): 272-278.

37 Taye BT, Amogne FK, Demisse TL, et al. Coronavirus disease 2019 vaccine acceptance and perceived barriers among university students in northeast Ethiopia: a cross-sectional study. Clin Epidemiol Glob Health. 2021;12:100848.

38 Shitu K, Wolde M, Handebo S, Kassie A. Acceptance and willingness to pay for COVID-19 vaccine among school teachers in Gondar City, Northwest Ethiopia. Trop Med Health. 2021;49(1):1-12.
39 Handebo S, Wolde M, Shitu K, Kassie A. Determinant of intention to receive COVID19 vaccine among school teachers in Gondar City, Northwest Ethiopia. PLoS One. 2021;16(6), e0253499.

40 Belsti Y, Gela YY, Akalu Y, et al. Willingness of Ethiopian population to receive COVID-19 vaccine. J Multidiscip Healthc. 2021;14:1233.

41 Zewude B, Belachew A. Intention to receive the second round of COVID-19 vaccine among healthcare workers in Eastern Ethiopia. Infect Drug Resist. 2021;14:3071.

42 Guangul BA, Georgescu G, Osman M, et al. Healthcare workers attitude towards SARS-COVID-2 vaccine, Ethiopia. Glob J Infect Dis Clin Research. 2021;7(1), 043-048.

43 Dereje N, Tesfaye A, Tamene B, et al. COVID-19 Vaccine Hesitancy in Addis Ababa, Ethiopia: A Mixed-Methods Study. medRxiv; 2021.

44 Daly M, Robinson E. Willingness to Vaccinate against COVID-19 in the US: Longitudinal Evidence from a Nationally Representative Sample of Adults from April-October 2020. medRxiv; 2020.

45 Paul E, Steptoe A, Fancourt D. Anti-vaccine Attitudes and Risk Factors for Not Agreeing to Vaccination against COVID-19 Amongst 32,361 UK Adults: Implications for Public Health Communications. Available at SSRN 3716874. 2020.

46 Roozenbeek J, Schneider CR, Dryhurst S, et al. Susceptibility to misinformation about COVID-19 around the world. R Soc Open Sci. 2020;7(10):201199.

47 Dodd R, Cvejic E, Bonner C, Pickles K, McCaffery K. Sydney health literacy lab COVID-19 group. Willingness to vaccinate against COVID-19 in Australia. Lancet Infect Dis. 2020, 30559-4.

48 Nehal KR, Steendam LM, Campos Ponce M, van der Hoeven M, Smit GSA. Worldwide vaccination willingness for COVID-19: a systematic review and meta-analysis. Vaccines. 2021;9(10):1071.

49 Iguacel I, Maldonado AL, Ruiz-Cabello AL, et al. Attitudes of healthcare professionals and general population toward vaccines and the intention to Be vaccinated against COVID-19 in Spain. Front Public Health. 2021;9.

50 BIO S. Status of COVID-19 Vaccines within WHO EUL/PQ Evaluation Process. 2021.

51 Rhodes A, Hoq M, Measey M-A, Danchin M. Intention to vaccinate against COVID-19 in Australia. Lancet Infect Dis. 2021;21(5):e110.

52 Sherman SM, Smith LE, Sim J, et al. COVID-19 vaccination intention in the UK: results from the COVID-19 vaccination acceptability study (CoVAccS), a nationally representative cross-sectional survey. Hum Vaccines Immunother. 2021;17(6): 1612-1621.

53 Böger B, Fachi MM, Vilhena RO, Cobre AF, Tonin FS, Pontarolo R. Systematic review with meta-analysis of the accuracy of diagnostic tests for COVID-19. Am J Infect Control. 2021;49(1):21-29.

54 Harapan H, Wagner AL, Yufika A, et al. Willingness-to-pay for a COVID-19 vaccine and its associated determinants in Indonesia. Hum Vaccines Immunother. 2020;16 (12):3074-3080.

55 Wang J, Jing R, Lai X, et al. Acceptance of COVID-19 vaccination during the COVID19 pandemic in China. Vaccines. 2020;8(3):482.

56 Gellman MD, Turner JR. Encyclopedia of Behavioral Medicine. New York, NY, USA: Springer; 2013.

57 Nzaji MK, Ngombe LK, Mwamba GN, et al. Acceptability of vaccination against COVID-19 among healthcare workers in the Democratic Republic of the Congo. Pragmatic Observational Res. 2020;11:103.

58 Al-Qerem WA, Jarab AS. COVID-19 vaccination acceptance and its associated factors among a Middle Eastern population. Front Public Health. 2021;9:34. 